\title{
KAJIAN PENGGUNAAN DATA HUJAN SATELIT TRMM UNTUK PERENCANAAN TALANG AIR IRIGASI PADA DAERAH IRIGASI NGARUM
}

\author{
Teguh Yuono \\ Program Studi Teknik Sipil, Fakultas Teknik, Universitas Tunas Pembangunan, Surakarta \\ teguh.yuono@lecture.utp.ac.id \\ Erni Mulyandari \\ Program Studi Teknik Sipil, Fakultas Teknik, Universitas Tunas Pembangunan, Surakarta \\ erni.mulyandari@lecture.utp.ac.id
}

\begin{abstract}
Abstrak
Perencanaan talang air umumnya berada di daerah yang aksesnya sulit terjangkau dan data hujan manual yang tersedia untuk perencanaan biasanya sangat jauh dari lokasi. Penelitian ini bertujuan untuk membandingkan besarnya debit inflow yang akan digunakan untuk merencanakan dimensi talang air dengan menggunakan data hujan manual dan data hujan satelit (TRMM). Hal ini berguna ketika perencanaan tidak tersedia data hujan manual. Hasil akhir dari perencanaan talang air ini adalah menghitung besarnya rencana anggaran biaya yang akan digunakan untuk proses kontruksi. Tahap pertama diawali dengan melakukan uji kepanggahan data hujan manual kemudian mendownload data hujan satelit. Data hujan satelit yang akan digunakan berdasarkan dari nilai koefisien korelasi tertinggi antara data hujan manual dengan data hujan satelit baik secara harian maupun setengah bulanan. Perhitungan debit inflow diperoleh berdasarkan dari debit kebutuhan air irigasi maksimum di setiap data hujan (manual maupun satelit). Hasil penelitian menunjukkan bahwa adanya kesamaan antara debit inflow dari data hujan manual dengan data hujan satelit walaupun di bulan yang berbeda. Berdasarkan debit inflow tersebut diperoleh dimensi talang air yaitu $b=0,5 \mathrm{~m}$ dan $\mathrm{h}=0,5 \mathrm{~m}$. Besarnya rencana anggaran biaya dari pembuatan talang air tersebut adalah sekitar Rp 35,934,545.52.
\end{abstract}

Kata kunci: TRMM, data hujan permukaan, talang air, rencana anggaran biaya.

\begin{abstract}
Gutter planning is commonly located in an area where the access is difficult to reach and the availability of the manual rainfall data used for planning is extremely distant from the location. This study aims at comparing the amount of inflow discharge that will be utilized to plan the gutter dimensions using the manual rainfall data and satellite rainfall data (TRMM). This is beneficial when the planning of the manual rainfall data is unavailable. The final result of this gutter planning is to calculate the amount of the budget plan that will be used for the construction process. The first stage begins with the manual rain data ductility test then downloading the satellite rain data. The employed satellite rain data is based on the highest correlation-coefficient value between manual rainfall data and satellite rainfall data both daily and semimonthly. The calculation of the inflow discharge is obtained based on the maximum discharge of irrigation water needs in each rain data (whether manual or satellite). The result shows that there is a similarity between the inflow discharge from manual rain data and satellite rain data even if in diverse months. Based on the inflow debit, it is obtained the gutter dimensions i.e. $\mathrm{b}=0.5 \mathrm{~m}$ and $\mathrm{h}=0.5 \mathrm{~m}$. The amount of the planned budget for the manufacture of the gutter is around IDR 35,934,545.52.
\end{abstract}

Keywords: TRMM, manual rainfall data, gutter, budget plan 


\section{PENDAHULUAN}

Daerah Irigasi (DI) Ngarum yang terletak di Desa Bener Kecamatan Grampal Kabupaten Sragen memiliki luas daerah irigasi sekitar 28 Ha. DI Ngarum sendiri merupakan daerah irigasi dengan tingkat kewenangan kabupaten yang berarti menjadi kewenangan Kabupaten Sragen.

Perencanaan talang air di DI Ngarum dilakukan berdasarkan dari survei lokasi yang mengharuskan perubahan talang air yang semula hanya menggunakan pipa pralon (Gambar 1) dan kemudian akan direncanakan pembangunan talang air dengan menggunakan beton bertulang. Hal tersebut dilakukan guna memperlancar air irigasi dan mengurangi resiko kebocoran air akibat penggunaan pipa pralon.

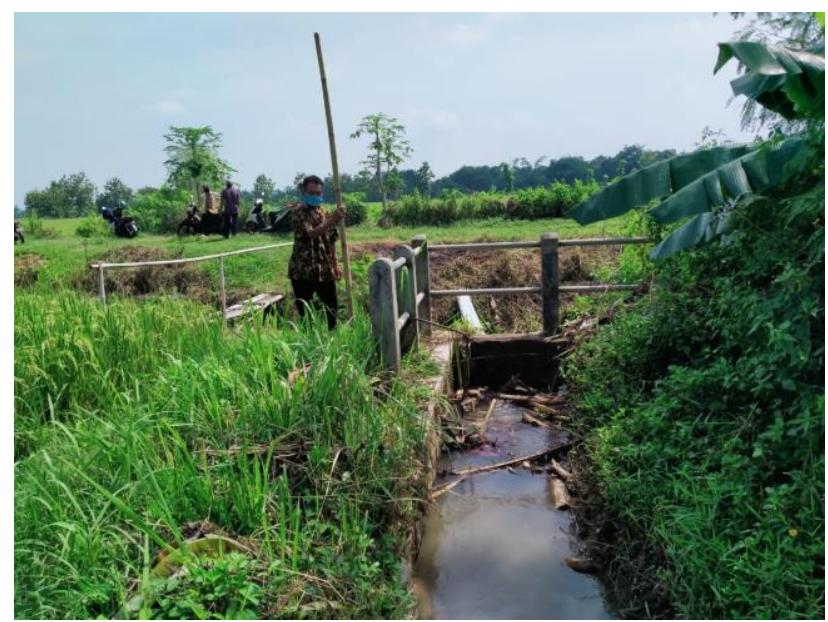

Gambar 1. Kondisi Pipa Pralon (Talang) Irigasi DI Ngarum

Pada penelitian kali ini menitik beratkan pada perhitungan debit kebutuhan air irigasi sebagai debit inflow untuk talang air irigasi. Debit inflow tersebut dicari menggunakan dua metode yaitu dengan data hujan permukaan dan data hujan satelit dalam hal ini adalah Tropical Rainfall Measuring Mission (TRMM).

Penelitian mengenai data hujan terukur manual dengan data hujan satelit TRMM telah banyak dilakukan seperti Mamenun, dkk (2014) melakukan validasi TRMM terhadap data observasi di wilayah hujan monsun (Lampung, Jawa Timur, Kalimantan Selatan), pola hujan equatorial (Sumatera Utara, Kalimantan Barat), dan pola lokal (Maluku). Analisis statistika digunakan untuk menghitung nilai koreksi, koefisien determinasi, RMSE (Root Mean Square Error), MAE (Mean Absolute Error) dan relatif bias antara daya hujan TRMM sebelum dikoreksi dengan data hujan TRMM yang telah dikoreksi.

Syaifullah, M. D. (2014) melakukan penelitian mengenai validasi data TRMM terhadap data curah hujan aktual di tiga DAS (Daerah Aliran Sungai) di Indonesia yaitu DAS Citarum, DAS Sutami Brantas, dan DAS Larona. Secara umum nilai curah hujan TRMM Jaxa mempunyai pola yang mengikuti curah hujan pengamatan (aktual) sehingga dapat dikatakan bahwa data satelit TRMM dapat digunakan untuk mengatasi keterbatasan data curah hujan di wilayah Indonesia.

Noor, Riza dkk (2016) melakukan penelitian mengenai pemanfaatan data hujan satelit TRMM untuk pemetaan zona agroklimat Oldeman di Kalimantan Selatan dan diperoleh kesimpulan bahwa hasil validasi data sangat memungkinkan untuk memanfaatkan data Satelit TRMM sebagi salah satu data suplemen atau pengganti data curah hujan permukaan.

Orfa, L.E. dkk (2018) melakukan penelitian menggunakan data TRMM untuk analisis hidrologi dan hasil dari penelitian tersebut 
adalah data hujan satelit TRMM merupakan data pembacaan dari citra satelit di mana banyak faktor yang perlu diperhatikan mulai dari pengambilan data melalui grid-grid sesuai luasan tertentu sehingga didapat kesesuaian dengan data obeservasi di stasiun hujan.

Mulyandari, E dkk (2020) melakukan penelitian mengenai validasi data hujan satelit dalam hal ini TRMM dan PERSIANN terhadap data hujan permukaan di DAS Telaga Lebur dan hasilnya data hujan satelit TRMM lebih baik digunakan dibandingkan dengan PERSIANN.

Raharjo, B dkk (2020) melakukan penelitian menggunakan data curah hujan satelit TRMM untuk menghitung bak tampungan bangunan ABSAH (Akuifer Buatan dan Simpanan Air Hujan) di Pulau Sumba dan diperoleh hasil koefisien korelasi sebesar 0,78 sehingga data hujan satelit tersebut dapat digunakan untuk menentukan volume bak tampungan ABSAH.

Sedangkan untuk penelitian mengenai talang air irigasi di Indonesia mayoritas berdasarkan pada Kriteria Perencanaan (KP) Irigasi khususnya pada KP-04 bagian Bangunan.

Pada KP-04 bagian Bangunan untuk subbab talang dan flum sendiri dibagi menjadi beberapa pokok bahasan seperti potongan melintang, kemiringan dan kecepatan, peralihan, tinggi jagaan, bahan, sampai dengan standar ukuran dan penulangan talang.

Tujuan dari penelitian ini adalah untuk membandingkan hasil debit inflow dari data hujan manual dengan data hujan satelit yang akan digunakan sebagai dasar dalam menentukan besarnya dimensi talang air.

\section{METODE PENELITIAN}

\section{A. Lokasi Penelitian}

Letak bangunan talang air yang akan dibangun memiliki koordinat $\mathrm{X}=507170.05 \mathrm{mT}$ dan $Y=9180176.83 \mathrm{mS}$. Talang air DI Ngarum merupakan talang air di bangunan tersier. Untuk lebih jelasnya dapat dilihat pada Gambar 2.

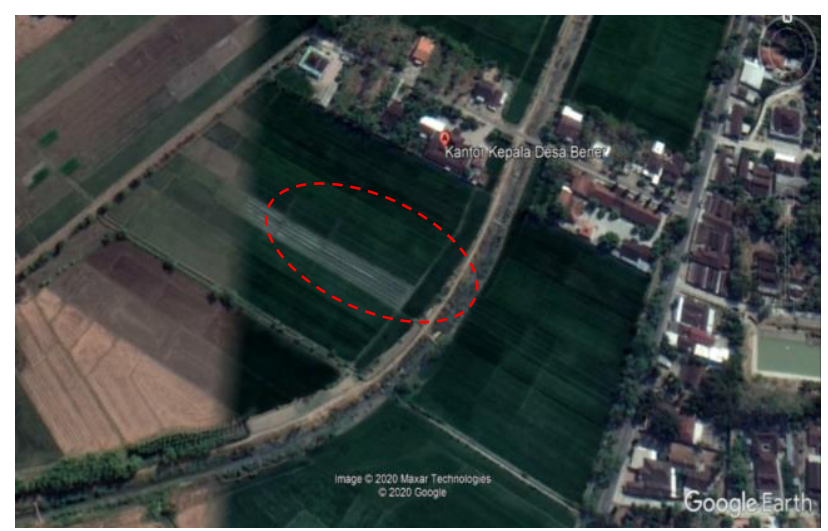

Gambar 2. Lokasi Pipa Pralon (Talang) Irigasi DI Ngarum

\section{B. Pengumpulan Data}

Pada penelitian ini menggunakan 2 tipe data yaitu data primer yang berasal dari wawancara terhadap petani mengenai awal tanam dan juga jenis tanaman yang sering ditanam di lokasi penelitian. Selain data primer diperlukan juga data sekunder yaitu data curah hujan permukaan atau manual di lokasi penelitian dalam hal ini menggunakan data klimatologi yang diperoleh dari Badan Meteorologi, Klimatologi, dan Geofisika (BMKG) khususnya Data Klimatologi Pos Patihan sedangkan untuk data hujan satelit TRMM dapat diunduh melalui https://giovanni.gsfc.nasa.gov/giovanni

\section{Alat yang Digunakan}

Analisis data dalam penelitian ini menggunakan beberapa perangkat lunak seperti berikut. 
1. Cropwat versi 8.0 untuk menghitung Evapotranspirasi Potensial.

2. Ms. Excel untuk perhitungan korelasi data hujan manual dengan data hujan satelit TRMM, kebutuhan air irigasi, cek dimensi talang, dan RAB.

3. Ms. Word untuk penyusunan jurnal penelitian.

\section{Metode Analisis}

Data hujan dari BMKG Pos Patihan harus dilakukan uji kepanggahan sebelum digunakan. Salah satu uji kepanggahan yang sering digunakan dan terbukti lebih baik dibanding dengan jenis pengujian yang lain yaitu metode RAPS (Rescaled Adjusted Partial Sums). Setelah itu data hujan manual akan dibandingkan dengan data hujan satelit dalam hal ini menggunakan data hujan satelit TRMM.

Data hujan satelit TRMM sengaja tidak dilakukan validasi untuk mengetahui besarnya korelasi dengan data hujan manual secara langsung. Setelah itu masing-masing digunakan untuk mencari besarnya debit kebutuhan air irigasi sehingga nanti akan diperoleh besarnya perbedaan dari keduanya.

Hasil debit kebutuhan air irigasi akan diambil yang paling maksimum untuk proses pengecekan dimensi talang irigasi yang telah ditentukan. Setelah dimensi talang irigasi ditetapkan akan dilakukan perhitungan rencana anggaran biaya (RAB) yang nantinya dapat bermanfaat untuk Perkumpulan Petani Pemakai Air (P3A) setempat.

\section{HASIL DAN PEMBAHASAN}

Sebelum data hujan manual digunakan, maka data hujan tersebut wajib dilakukan uji konsistensi. Hasil uji konsistensi dengan metode RAPS untuk Data Hujan Pos Patihan dapat dilihat seperti pada Tabel 1.

Tabel 1.

Hasil Perhitungan Uji RAPS

\begin{tabular}{ccccc}
\hline \hline $\mathrm{n}$ & Tahun & $\Sigma \mathrm{P}$ & $\mathrm{S}_{\mathrm{k}} * *$ & $\left|\mathrm{~S}_{\mathrm{k}} * *\right|$ \\
\hline 1 & 2008 & 2657.0 & 0.55 & 0.55 \\
2 & 2009 & 3679.0 & 2.17 & 2.17 \\
3 & 2010 & 3823.0 & 3.94 & 3.94 \\
4 & 2011 & 2379.0 & 4.19 & 4.19 \\
5 & 2012 & 1900.0 & 3.94 & 3.94 \\
6 & 2013 & 2723.0 & 4.55 & 4.55 \\
7 & 2014 & 1694.0 & 4.09 & 4.09 \\
8 & 2015 & 1196.0 & 3.09 & 3.09 \\
9 & 2016 & 2306.5 & 3.27 & 3.27 \\
10 & 2017 & 1717.5 & 2.83 & 2.83 \\
11 & 2018 & 728.0 & 1.34 & 1.34 \\
12 & 2019 & 860.5 & 0.00 & 0.00 \\
\hline \hline
\end{tabular}

Jika dibandingkan dengan $Q_{\text {kritik }}$ dan $\mathrm{R}_{\text {kritik}}$, nilai maksimum $\left|\mathrm{Sk}^{* *}\right|$ dan maksimum $\mathrm{Sk}^{* *}$ minimum $\mathrm{S}_{\mathrm{k}} * *$ masih lebih kecil sehingga dapat dikatakan bahwa data hujan di Pos Patihan adalah konsisten dan dapat langsung digunakan untuk analisis lebih lanjut.

Selanjutnya mendownload data hujan satelit dengan rentang waktu sama dengan data hujan manual yaitu mulai dari tahun 2008 sampai tahun 2019. Data hujan manual dan TRMM nanti akan dibandingkan dan dicari korelasi terkuatnya untuk menghitung debit kebutuhan air irigasi.

Adapun data yang dibandingkan adalah data hujan harian dan data hujan setengah bulanan. Untuk perbandingan data hujan harian dapat dilihat pada Gambar 3 sedangkan untuk perbandingan data hujan setengah bulanan (15 harian) dapat dilihat pada Gambar 4. 


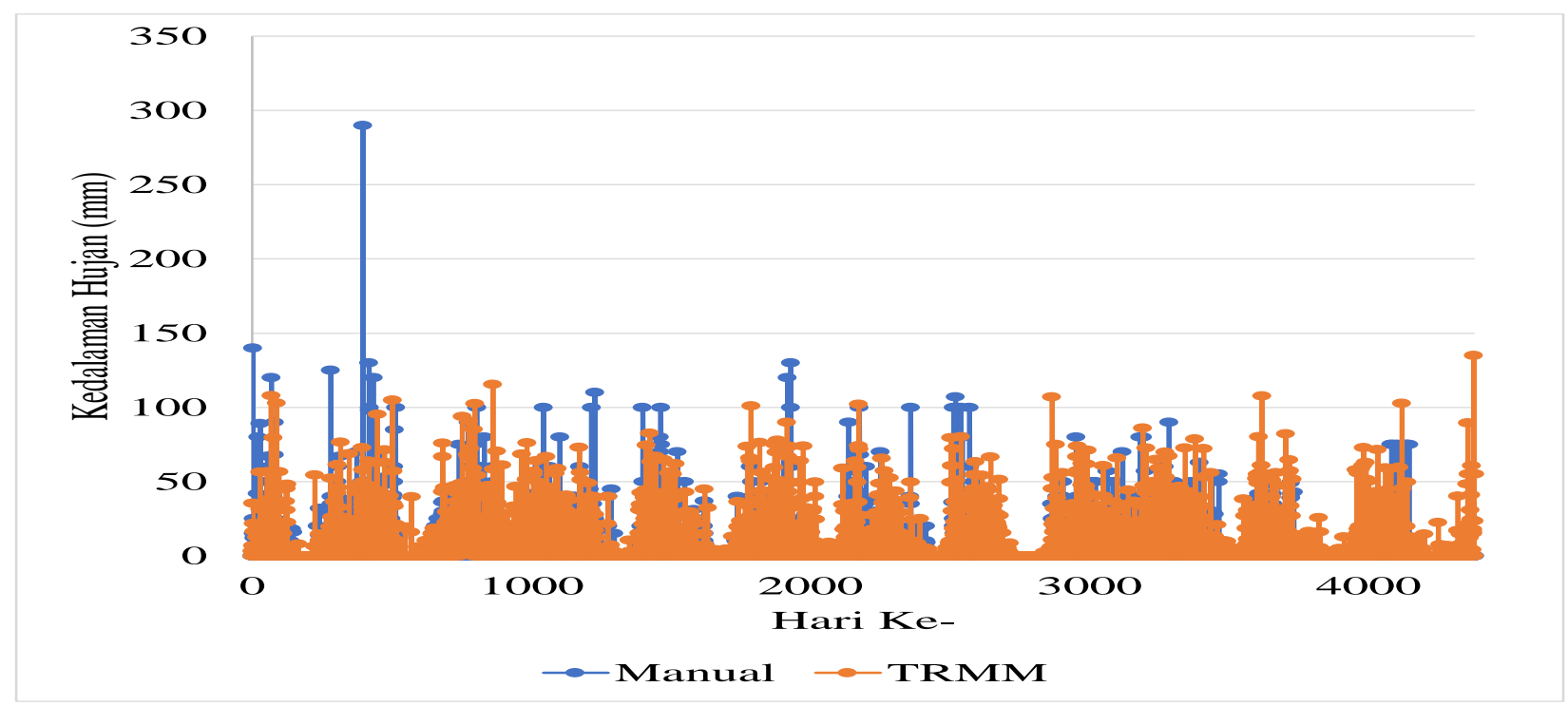

Gambar 3. Perbandingan Hujan Harian

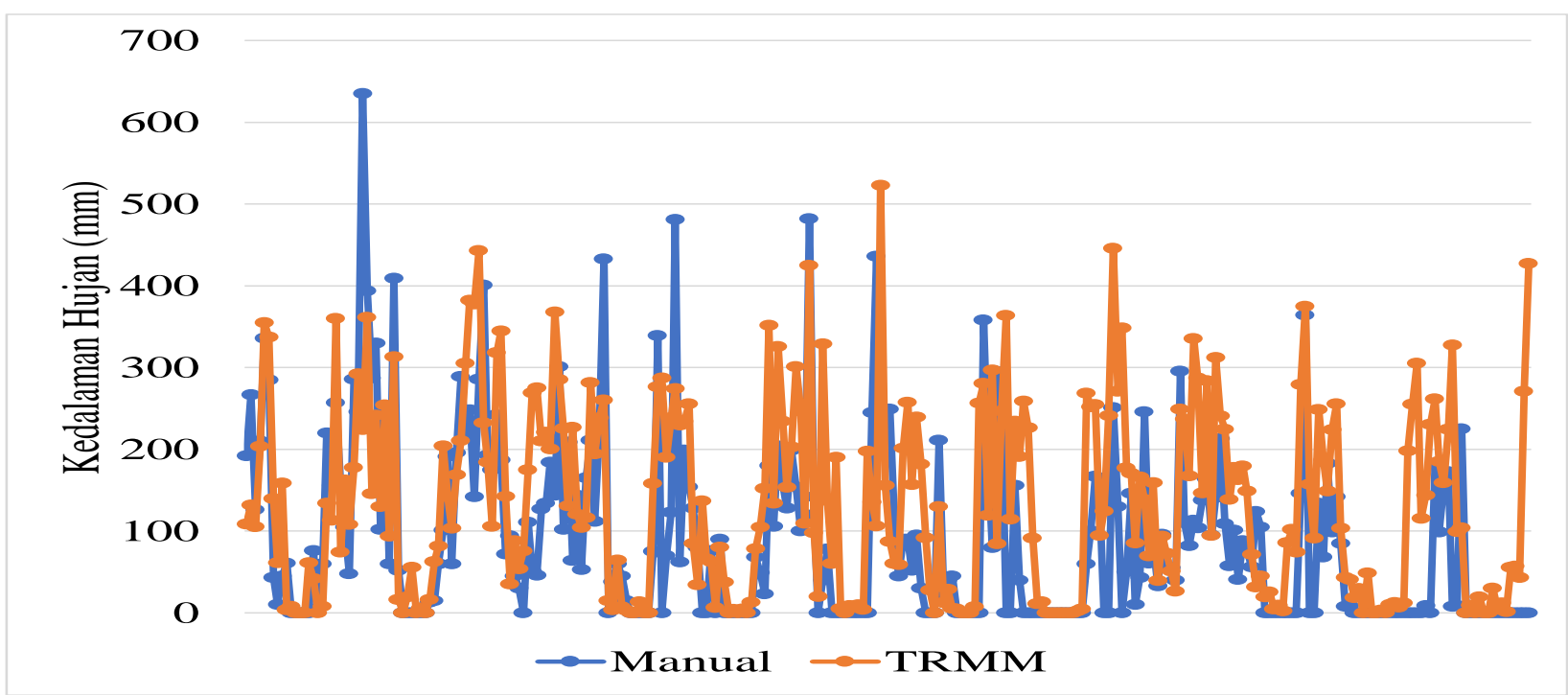

Gambar 4. Perbandingan Hujan 15 Harian

Koefisien korelasi dicari dari perbandingan hujan setengah bulanan.

hujan harian dan perbandingan hujan 15 harian. Analisis selanjutnya yaitu menentukan Untuk data hujan harian (Manual vs TRMM) besarnya evapotranspirasi potensial yang akan diperoleh besarnya koefisien korelasi 0,22 yang digunakan untuk menghitung besarnya berarti tingkat korelasinya sangat lemah kebutuhan air irigasi. Perhitungan sedangkan untuk data hujan 15 harian diperoleh evapotranspirasi menggunakan metode Penmanbesarnya nilai korelasi adalah 0,59 yang berarti Monteith yang akan dibantu dengan program korelasinya kuat. Sehingga diputuskan CROPWAT versi 8.0. Adapun hasil melakukan perbandingan debit untuk evapotranspirasi potensial di lokasi penelitian perencanaan talang air irigasi adalah dengan dapat dilihat pada Tabel 2. menggunakan data hujan 15 harian atau data 
Tabel 2.

Hasil Perhitungan Evapotranspirasi Potensial

\begin{tabular}{|c|c|c|c|}
\hline No & Bulan & Periode & ETo \\
\hline \multirow{2}{*}{1} & \multirow{2}{*}{ Januari } & 1 & 3.80 \\
\hline & & 2 & 3.80 \\
\hline \multirow{2}{*}{2} & \multirow{2}{*}{ Februari } & 1 & 3.48 \\
\hline & & 2 & 3.48 \\
\hline \multirow{2}{*}{3} & \multirow{2}{*}{ Maret } & 1 & 4.89 \\
\hline & & 2 & 4.89 \\
\hline \multirow{2}{*}{4} & \multirow{2}{*}{ April } & 1 & 4.47 \\
\hline & & 2 & 4.47 \\
\hline \multirow{2}{*}{5} & \multirow{2}{*}{ Mei } & 1 & 4.88 \\
\hline & & 2 & 4.88 \\
\hline \multirow{2}{*}{6} & \multirow{2}{*}{ Juni } & 1 & 4.38 \\
\hline & & 2 & 4.38 \\
\hline \multirow{2}{*}{7} & \multirow{2}{*}{ Juli } & 1 & 3.94 \\
\hline & & 2 & 3.94 \\
\hline \multirow{2}{*}{8} & \multirow{2}{*}{ Agustus } & 1 & 4.11 \\
\hline & & 2 & 4.11 \\
\hline \multirow{2}{*}{9} & \multirow{2}{*}{ September } & 1 & 4.21 \\
\hline & & 2 & 4.21 \\
\hline \multirow{2}{*}{10} & \multirow{2}{*}{ Oktober } & 1 & 4.19 \\
\hline & & 2 & 4.19 \\
\hline \multirow{2}{*}{11} & \multirow{2}{*}{ November } & 1 & 3.58 \\
\hline & & 2 & 3.58 \\
\hline \multirow{2}{*}{12} & \multirow{2}{*}{ Desember } & 1 & 3.45 \\
\hline & & 2 & 3.45 \\
\hline
\end{tabular}

Untuk selanjutnya dilakukan perhitungan

kebutuhan air irigasi di DI Ngarum dengan pola tanam Padi - Padi - Padi yang umumnya dimulai pada bulan Februari. Adapun perbandingan penggunaan data hujan manual dengan TRMM dapat dilihat pada Tabel 3.

Pada prinsipnya bukaan pintu irigasi selalu berdasarkan pada kebutuhan air irigasi, sehingga untuk melakukan pengecekan perencanaan talang air irigasi digunakan besarnya debit kebutuhan air irigasi sebagai debit inflow.

Berdasarkan data debit tersebut di atas dihitung besarnya nilai korelasi antar keduanya dan hasil nilai korelasinya adalah 0,93 yang berarti hasil debit kebutuhan air irigasi tersebut memiliki korelasi sangat kuat. Debit maksimum keduanya juga sama walaupun di bulan yang berbeda yaitu sebesar $101.25 \mathrm{l} / \mathrm{d}$ atau hanya berkisar $0,10 \mathrm{~m}^{3} / \mathrm{d}$.

Tabel 3.

Perbandingan Debit Kebutuhan Air Irigasi $\left(\mathrm{Q}_{\text {in }}\right)$

\begin{tabular}{|c|c|c|c|c|}
\hline \multirow{2}{*}{ No } & \multirow{2}{*}{ Bulan } & \multirow{2}{*}{ Periode } & \multicolumn{2}{|c|}{$\mathrm{Q}_{\text {in }}(\mathrm{l} / \mathrm{d})$} \\
\hline & & & Manual & TRMM \\
\hline \multirow{2}{*}{1} & \multirow{2}{*}{ Januari } & 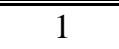 & 7.83 & 0.00 \\
\hline & & 2 & 0.00 & 0.00 \\
\hline \multirow{2}{*}{2} & \multirow{2}{*}{ Februari } & 1 & 67.36 & 60.41 \\
\hline & & 2 & 73.47 & 46.31 \\
\hline \multirow{2}{*}{3} & \multirow{2}{*}{ Maret } & 1 & 27.82 & 10.24 \\
\hline & & 2 & 36.39 & 17.81 \\
\hline \multirow{2}{*}{4} & \multirow{2}{*}{ April } & 1 & 48.40 & 5.45 \\
\hline & & 2 & 48.20 & 28.75 \\
\hline \multirow{2}{*}{5} & \multirow{2}{*}{ Mei } & 1 & 33.09 & 17.99 \\
\hline & & 2 & 9.97 & 8.16 \\
\hline \multirow{2}{*}{6} & \multirow{2}{*}{ Juni } & 1 & 101.25 & 100.47 \\
\hline & & 2 & 101.25 & 101.25 \\
\hline \multirow{2}{*}{7} & \multirow{2}{*}{ Juli } & 1 & 31.58 & 31.58 \\
\hline & & 2 & 31.58 & 31.58 \\
\hline \multirow{2}{*}{8} & \multirow{2}{*}{ Agustus } & 1 & 31.49 & 31.49 \\
\hline & & 2 & 31.49 & 31.49 \\
\hline \multirow{2}{*}{9} & \multirow{2}{*}{ September } & 1 & 29.91 & 29.91 \\
\hline & & 2 & 9.97 & 9.97 \\
\hline \multirow{2}{*}{10} & \multirow{2}{*}{ Oktober } & 1 & 100.66 & 100.41 \\
\hline & & 2 & 100.66 & 97.26 \\
\hline \multirow{2}{*}{11} & \multirow{2}{*}{ November } & 1 & 29.61 & 0.00 \\
\hline & & 2 & 29.61 & 0.00 \\
\hline \multirow{2}{*}{12} & \multirow{2}{*}{ Desember } & 1 & 28.03 & 0.00 \\
\hline & & 2 & 28.03 & 0.00 \\
\hline
\end{tabular}

Berdasarkan tabel perhitungan dimensi dan hidrolik talang yang ada pada KP-04 (Hal 115), di mana untuk debit terkecil yaitu $0,15 \mathrm{~m}^{3} / \mathrm{d}$ dimensi talang air yang digunakan adalah $\mathrm{B}=0,5 \mathrm{~m}$ dan $\mathrm{H}=0,5 \mathrm{~m}$ yang dapat didetailkan seperti pada Gambar 5.

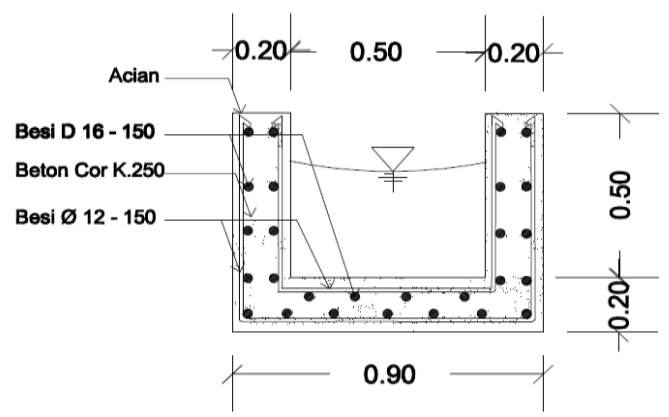

Gambar 5. Detail Talang Air DI Ngarum Desa Bener

Selanjutnya dicari besarnya RAB untuk pekerjaan talang air tersebut. Adapun rinciannya dapat dilihat seperti pada Tabel 4. 
Tabel 4.

RAB Pekerjaan Bangunan Talang

\begin{tabular}{|c|c|c|c|}
\hline A. & |PEKERJAAN BANGUNAN TALANG AIR & & \\
\hline \multirow[t]{3}{*}{1} & Pekerjaan Tanah & & \\
\hline & 1.1. Galian tanah biasa (cara manual) & $\mathrm{Rp}$ & $334,985.00$ \\
\hline & 1.2. Urugan tanah kembali & $\mathrm{Rp}$ & $65,950.65$ \\
\hline \multirow[t]{5}{*}{2} & Pekerjaan Pasangan & & \\
\hline & 2.1. Pasangan batu 1 PC : 5 PP & $\mathrm{Rp}$ & $8,899,704.00$ \\
\hline & 2.2. Plesteran $1 \mathrm{PC}: 4 \mathrm{PP}$, tebal $1,5 \mathrm{~cm}$ & $\mathrm{Rp}$ & $478,176.00$ \\
\hline & 2.3. Acian, tebal $1 \mathrm{~mm}$ & $\mathrm{Rp}$ & $294,960.00$ \\
\hline & 2.4. Siaran dengan mortar tipe $\mathrm{S}(1 \mathrm{PC}: 3 \mathrm{PP})$ & $\mathrm{Rp}$ & $1,830,312.00$ \\
\hline \multirow[t]{5}{*}{3} & Pekerjaan Footplat beton bertulang & & \\
\hline & 3.1. Lantai kerja & $\mathrm{Rp}$ & $149,101.00$ \\
\hline & 3.2. Begisting & $\mathrm{Rp}$ & $230,520.00$ \\
\hline & 3.3. Pembesian D 19-150 & $\mathrm{Rp}$ & $4,637,908.80$ \\
\hline & 3.4. Cor beton K.250 & $\mathrm{Rp}$ & $979,204.71$ \\
\hline \multirow[t]{4}{*}{4} & Pilar/kolom beton bertulang 30x90 cm & & \\
\hline & 4.1. Begisting & $\mathrm{Rp}$ & $897,494.40$ \\
\hline & 4.2. Pembesian 18 D 19 , begel $\varnothing 10-150$ & $\mathrm{Rp}$ & $4,535,305.74$ \\
\hline & 4.3. Cor beton K.250 & $\mathrm{Rp}$ & $1,165,253.60$ \\
\hline \multirow[t]{7}{*}{5} & Dinding dan lantai saluran beton bertulang & & \\
\hline & 5.1. Begisting & $\mathrm{Rp}$ & $522,720.00$ \\
\hline & 5.2. Pembesian melintang $\varnothing 12-150$ & $\mathrm{Rp}$ & $2,658,398.40$ \\
\hline & 5.3. Pembesian memanjang D 16-150 & $\mathrm{Rp}$ & $4,818,592.80$ \\
\hline & 5.4. Cor beton K.250 & $\mathrm{Rp}$ & $2,790,733.42$ \\
\hline & 5.5. Acian & $\mathrm{Rp}$ & $645,225.00$ \\
\hline & TOTAL A & $\mathbf{R p}$ & $35,934,545.52$ \\
\hline
\end{tabular}

\section{KESIMPULAN}

Adapun kesimpulan yang dapat diambil dalam penelitian ini yaitu:

1. Adanya kesamaan antara debit maksimum data hujan manual dengan data hujan satelit walaupun di bulan yang berbeda yaitu sebesar $101.25 \mathrm{l} / \mathrm{d}$ atau $0,10 \mathrm{~m}^{3} / \mathrm{d}$

2. Berdasarkan data debit maksimum pada poin 1 diperoleh besarnya dimensi talang air adalah $b=0,5 \mathrm{~m}$ dan $\mathrm{h}=0,5 \mathrm{~m}$ dengan besarnya anggaran biaya yang dibutuhkan adalah sekitar Rp 35,934,545.52.

\section{UCAPAN TERIMA KASIH}

Penulis mengucapkan terima kasih kepada P3A Marsudi Tani atas bantuannya dalam penelitian ini khususnya mengenai pola tanam dan awal tanam di DI Ngarum.

\section{DAFTAR PUSTAKA}

Departemen Pekerjaan Umum Direktorat Jenderal Pengairan, 1986, Kriteria Perencanaan Bagian Bangunan (KP 04), Departemen Pekerjaan Umum Direktorat Jenderal Pengairan.

Jonathan, Sarwono. 2006. Metode Penelitian Kuantitatif dan Kualitatif. Graha Ilmu. Yogyakarta.

Mamenun, Pawitan, H., Sophaheluwakan, A. 2014. Validasi dan Koreksi Data Satelit TRMM pada Tiga Pola Hujan di Indonesia. Jurnal Meteorologi Dan Geofisika. Vol. 15 No. 1 Tahun 2014 : 1323

Mulyandari, E., \& Susila, H. (2020). VALIDASI DATA CURAH HUJAN SATELIT TRMM DAN PERSIANN DALAM ANALISIS DEBIT BANJIR RENCANA DI DAS TELAGA LEBUR. Jurnal Teknik Sipil Dan Arsitektur, 25(2), 16-22. 
Noor, Riza \& Ruslan, Muhammad \& Rusmayadi, Gusti \& Badaruddin, Badaruddin. (2016). PEMANFAATAN DATA SATELIT TROPICAL RAINFALL MEASURING MISSION (TRMM) UNTUK PEMETAAN ZONA AGROKLIMAT OLDEMAN DI KALIMANTAN SELATAN. EnviroScienteae. 12. 267. 10.20527/ es.v12i3.2452.

Orfa, L. E., \& Samad, A. (2018). KAJIAN PENGGUNAAN DATA TRMM (TROPICAL RAINFALL MEASURING MISSIONS) UNTUK ANALISIS HIDROLOGI (STUDI KASUS PADA BENDUNG LOLAK KAB. BOLAANG MONGONDOW, SULAWESI UTARA. SENTRA, 34-39.

Raharjo, B., Soenarto, B., Seizarwati, W. (2020). PENGGUNAAN DATA CURAH UJAN (TRMM) UNTUK PERHITUNGAN AK TAMPUNGAN BANGUNAN ABSAH DI TERMINAL BANDARA UMBU MEHANG KUNDA, WAINGAPU, PULAU SUMPA. Jurnal Sain dan Teknologi Teknik Utama, Edisi Khusus, No. 2, Agustus 2020.

Sri Harto Br., 2009. Hidrologi: Teori, Masalah, Penyelesaian. Nafiri Offset. Yogyakarta

Syaifullah, M.D. (2014). VALIDASI DATA TRMM TERHADAP DATA CURAH HUJAN AKTUAL DI TIGA DAS DI INDONESIA. Jurnal Meteorologi Dan Geofisika, Vol. 15 No. 2 TAHUN 2014 : 109-118 